\title{
Frontotemporal Dementia: Recommendations for Therapeutic Studies, Designs, and Approaches
}

\author{
Morris Freedman
}

\begin{abstract}
Frontotemporal dementia (FTD) is one of three neurobehavioural syndromes produced by frontotemporal lobar degeneration. Despite the importance of FTD as a cause of dementia, especially in younger age groups, and a rationale for therapies targeting serotonergic and dopaminergic systems, there have been no large scale treatment trials in FTD. Moreover, there is no consensus on standards to facilitate comparison across therapeutic trials. This paper reviews the literature on therapeutic trials in FTD and outlines general recommendations for standards related to the development of future treatment studies in this disorder. Drugs tested in FTD include trazodone, galantamine, idazoxan, lithium plus fluoxetine, lithium plus paroxetine, SSRIs, l-deprenyl, moclobemide, methylphenidate, piracetam, rivastigmine, donepezil, olanzapine, risperidone, amantadine, guanfacine, allopurinol, and bromocriptine. Improvement has been reported in FTD for all drugs except piracetam, guanfacine and galantamine, although there was improvement on galantamine in primary progressive aphasia. Whereas improvement has been reported for paroxetine and other SSRIs, as well as idazoxan and methylphenidate, paroxetine and idazoxan have also been reported to cause a decline in function, and a marginally significant decline has been reported for methylphenidate. In addition, patients with Pick's disease, which is part of the spectrum of frontotemporal lobar degeneration, showed improvement on calcium EDTA. Six studies are double-blind placebo-controlled trials: two reports of cases using idazoxan and group trials using trazodone, paroxetine, galantamine and methylphenidate. It is recommended that experts in FTD arrive at a consensus to define standards for all clinical trials in FTD. These should include standards for diagnostic criteria, tests of severity, experimental design, and outcome measures.
\end{abstract}

RÉSUMÉ: Démence fronto-temporale, recommandations concernant les essais thérapeutiques, plans d'étude et approches. La démence frontotemporale (DFT) est l'un des trois syndromes neurocomportementaux résultant de la dégénérescence lobaire fronto-temporale. Malgré l'importance de la DFT comme cause de démence, surtout chez les gens moins âgés, et le fait que les systèmes sérotoninergique et dopaminergique soient une cible logique pour le développement de médicaments, aucun essai clinique de grande envergure n'a été effectué dans la DFT. De plus, il n'existe pas de consensus sur des standards qui faciliteraient la comparaison entre les essais cliniques. Cet article revoit la littérature sur les essais cliniques portant sur la DFT et formule des recommandations générales sur les standards à utiliser à l'avenir pour élaborer des essais cliniques pour cette maladie. Les médicaments qui ont été étudiés dans la DFT sont le trazodone, la galantamine, l'idazoxan, le lithium associé à la fluoxétine, le lithium associé à la paroxétine, les IRSSs, le 1-déprényl, le moclobémide, le méthylphénidate, le piracétam, la rivastigmine, le donépézil, l'olanzapine, la rispéridone, l'amantadine, la guanfacine, l'allopurinol et la bromocriptine. Une amélioration a été rapportée avec l'utilisation de tous ces médicaments dans la DFT sauf avec le piracétam, la guanfacine et la galantamine, bien qu'on ait observé une amélioration sous galantamine dans l'aphasie progressive primitive. Bien qu'une amélioration ait été rapportée sous paroxétine et d'autres IRSSs ainsi que sous idazoxan et sous méthylphénidate, un déclin fonctionnel causé par la paroxétine et l'idazoxan a également été rapporté et un déclin à peine significatif a également été rapporté avec le méthylphénidate. De plus, les patients atteints de la maladie de Pick, une maladie qui fait partie des dégénérescences lobaires fronto-temporales, se sont améliorés sous EDTA calcique. Six des études sont des essais en double insu contre placebo : deux comptes rendus de patients sous idazoxan et des essais cliniques avec le trazodone, la paroxétine, la galantamine et le méthylphénidate. Nous recommandons que les experts dans le domaine de la DFT établissent un consensus sur la définition de standards pour tous les essais cliniques sur la DFT, soit des standards sur les critères diagnostiques, les tests pour évaluer la sévérité, le plan des études et les critères d'évaluation des résultats.

Can. J. Neurol. Sci. 2007; 34: Suppl. 1 - S118-124

Frontotemporal lobar degeneration (FTLD) represents a spectrum of disorders comprised of three core syndromes: frontotemporal dementia (FTD), progressive nonfluent aphasia (PA), and semantic dementia (SD). ${ }^{1}$ Although a variety of pathologies underlie FTLD, ${ }^{2,3}$ the clinical presentation is determined by anatomical distribution of the lesions. ${ }^{1}$
From the Division of Neurology and Rotman Research Institute, Baycrest; Department of Medicine, Division of Neurology, Mount Sinai Hospital, University Health Network, and University of Toronto, Toronto, ON, Canada.

Received October 31, 2005. ACcepted in final form February 28, 2006 Reprint requests to: Morris Freedman, Division of Neurology, Baycrest, Brain Health Complex, Rm. 656, 3560 Bathurst Street, Toronto, Ontario, M6A 2E1, Canada. 
Involvement of orbitofrontal regions bilaterally produces FTD, left perisylvian damage gives rise to $\mathrm{PA}$, and lesions in the temporal poles and inferolateral cortex result in SD. ${ }^{2}$ The most common presentation is FTD. ${ }^{4,5}$ This paper reviews the current literature on therapeutic trials in FTD and outlines general recommendations for standards related to development of future treatment studies in this disorder.

Frontotemporal dementia usually occurs in individuals under the age of $70 .{ }^{6}$ In a population-based study of FTD in the Netherlands, Rosso et $\mathrm{al}^{7}$ found a maximum prevalence of 9.4 per 100,000 at 60-69 years of age. The prevalence was 3.6 per 100,000 from ages $50-59$ and 3.8 per 100,000 from ages 70-79. In a community-based study of FTD in the United Kingdom, Ratnavelli et $\mathrm{al}^{4}$ reported a prevalence of 15 per 100,000 in the 45-64 age group. In fact, they found that $15.7 \%$ of cases (17/108) with onset of dementia under age 65 years had FTLD, and that $12 \%(13 / 108)$ had FTD. The other cases had PA $(n=2)$ and SD $(n=2)$. In another study of a hospital-based series of 330 demented patients in Japan, Ikeda et $\mathrm{al}^{5}$ found that $12.7 \%$ had FTLD. Of these cases, $52.4 \%$ had FTD, 35.7\% had SD, and $11.9 \%$ had PA. Imamura et $\mathrm{al}^{8}$ found that $6.8 \%$ of their hospitalbased series had FTD. In neuropathological series, FTD comprised $17 \%$ and $8 \%$ of cases with dementia under age 70 years, ${ }^{9,10}$ and from $5-13 \%$ of all cases. ${ }^{9-12}$

Despite the importance of FTD as a cause of dementia, especially in younger age groups, and the rationale for potential therapies targeting serotonergic ${ }^{13-16}$ and dopaminergic ${ }^{14}$ systems, there have been no large scale treatment trials in FTD; ${ }^{17}$ and only six double-blind placebo-controlled studies: two reports of cases using idazoxan, an alpha 2 adrenoreceptor antagonist, ${ }^{18,19}$ and group trials using trazodone, a serotonergic agent, ${ }^{20}$ paroxetine, a selective serotonin reuptake inhibitor (SSRI), ${ }^{21}$ galantamine,${ }^{22}$ a cholinesterase inhibitor and methylphenidate, a drug that increases synaptic and extracellular dopamine and noradrenaline. ${ }^{23}$

Sahakian et al ${ }^{18}$ reported an FTD case treated with $40 \mathrm{mg}$ of idazoxan, administered on two occasions, using a double-blind placebo-controlled protocol. There was improvement on tasks sensitive to frontal lobe function (i.e., Tower of London test of planning, verbal fluency for categories, and percentage of correct detections made on a rapid visual information processing test of sustained attention), but there was no benefit on paired associates learning, pattern and spatial recognition, or digit span. The diagnostic criteria were not stated. Coull et al $^{19}$ reported three cases treated with idazoxan using a double-blind placebocontrolled design. Two doses were administered on two separate occasions. The patients met provisional operational criteria for dementia of the frontal lobe type. ${ }^{24}$ Outcome measures included pattern and spatial recognition, spatial working memory, Tower of London, rapid visual information processing, ID/ED attentional set-shifting task, paired associates learning, verbal fluency, delayed matching to sample, logical memory test, and digit span. Improvement was noted, particularly on tests of planning, sustained attention, verbal fluency, and episodic memory. However, there were deficits on a test of spatial working memory. Statistical analyses were not carried out in either of the two studies using idazoxan.

Lebert et $\mathrm{al}^{20}$ reported a multicentre, double-blind, placebocontrolled, cross-over trial in FTD using trazodone. The diagnosis was based on the Lund-Manchester criteria, ${ }^{25}$ and a score of $>3$ on the Frontal Behavioural Dysfunction Scale. Inclusion criteria included a total score $>8$ on the Neuropsychiatric Inventory (NPI) and a score $\geq 4$ for one of the following NPI items: delusions, hallucinations, aggression, depression/dysphoria, anxiety, disinhibition, irritability, abnormal motor behaviour, or sleep disorders. They studied 31 patients who were treated for two 6-week periods (placebotrazodone or trazodone-placebo sequence), and 26 patients completed the study. The primary outcome measure was the total NPI score, and secondary outcome measures were the Clinical Global Impression Improvement (CGI-I) and MMSE. There was a significant benefit of trazodone on total NPI score $(p=0.028)$ with improvement on eating disorders, agitation, irritability, and depression/dysphoria; however, there was no significant improvement measured by CGI-I $(\mathrm{p}=0.08)$ or $\operatorname{MMSE}(\mathrm{p}=0.1) .{ }^{20}$

Deakin et $\mathrm{al}^{21}$ reported a double-blind placebo-controlled trial in ten subjects with FTD using paroxetine. There were complete data in six subjects. Diagnosis was based upon the criteria by Neary et al. ${ }^{1}$ All patients also conformed to local guidelines showing at least 5 of 12 clinical features. ${ }^{21}$ Outcome measures consisted of tests taken from the Cambridge Neuropsychological Test Automated Battery (CANTAB) and the CANTAB extensions. The tasks included immediate and delayed pattern recognition, spatial recognition, spatial span, spatial working memory, visual discrimination learning/attentional set shifting, decision-making 'Gamble', and paired-associates learning. The NPI and the Cambridge Behavioral Inventory were also administered. There was a decrease in performance on reversal shifts of the visual discrimination learning/attentional set shifting task $(\mathrm{p}=0.050)$ and delayed pattern recognition memory $(p=0.020)$. In addition, there was a decrease in performance on paired associates learning that neared significance $(p=0.056)$. There were no significant differences on the NPI or Cambridge Behavioral Inventory and no changes on the decision making task, spatial span, spatial recognition, spatial working memory, immediate pattern recognition, digit span, and verbal fluency.

Kertesz et $\mathrm{al}^{22}$ reported a study of galantamine in FTD and primary progressive aphasia. The latter term includes both PA and SD. ${ }^{26}$ The study was published in abstract form. Diagnostic criteria were not stated. After treatment for 18 weeks, patients entered a four week double-blind placebo-controlled withdrawal phase. Of 41 subjects screened, there were 36 who completed the open-label phase and 34 who completed the double-blind phase. Primary outcome measures consisted of the Frontal Behavioral Inventory (FBI), Aphasia Quotient of the Western Aphasia Battery (WAB), and the Clinical Global Impressions (CGI). Secondary outcome measures included an activities of daily living measure (ADCS-ADL-Inventory), MMSE, Dementia Rating Scale-2, NPI, and subscales of the WAB and FBI. In the placebo controlled withdrawal phase, there was significant benefit in primary progressive aphasia on the CGI $(\mathrm{p}=0.009)$. However, there was no improvement in the overall group on this measure. In addition, the Aphasia Quotient of the WAB remained stable in the active treatment group compared to placebo whereas the placebo group showed a decline.

Rahman et $\mathrm{al}^{23}$ carried out a double-blind-placebo-controlled cross-over study of methylphenidate, using a single dose of 40 
mg, in eight patients with FTD meeting Lund-Manchester criteria. Outcome measures included pattern recognition memory, spatial recognition memory, spatial span, spatial working memory, ID/ED attentional set-shifting, one-touch version of the CANTAB Tower of London test of spatial planning, and the Cambridge Gamble Task. There was an attenuation of risk-taking on the Cambridge Gamble Task. There was also a marginally significant detrimental effect on spatial span on the span score $(\mathrm{p}=0.096)$.

Based upon the above double-blind placebo-controlled studies, the best evidence to date for the treatment of FTD is for trazodone. However, the results require replication in larger well-controlled studies. Although the double-blind placebocontrolled trials of idazoxan and methylphenidate showed positive results on certain measures, these studies were based on a small number of cases and are not as compelling as the larger study on trazodone. Moreover, there was worsening of cognitive function on one measure using idazoxan (statistical analyses not carried out) and a marginally significant detrimental effect on a measure using methylphenidate. The galantamine trial did not show benefit in FTD but this study is notable in that there was improvement in primary progressive aphasia. Similarly to the comment on the trazodone study, the galantamine, idazoxan, and methylphenidate trials require replication.

Several other treatment trials have been carried out. However, these were not double-blind placebo-controlled. Nevertheless, these trials are included to provide an overview of the research to date on treatment of FTD. These studies will be briefly reviewed with a focus on diagnostic criteria, outcome measures, and results.

Lebert and Pasquier ${ }^{27}$ carried out a 6-week open label trial of trazodone in 14 consecutive patients with FTD who met LundManchester criteria including a SPECT pattern of an isolated frontotemporal uptake decrease. There was significant improvement on the following domains of the NPI: delusions, aggression, anxiety, irritability, depression, disinhibition, and aberrant motor behavior. There was no effect on the MMSE.

Anderson et $\mathrm{al}^{28}$ reported two patients with FTD and severe depressive illness who were treated with lithium plus an SSRI fluoxetine in one case and paroxetine in the other. Both cases showed improved mood. In one, there was no improvement in cognitive function, while in the other, there was improvement in memory but not in frontal lobe function. Diagnostic criteria for FTD and frontal lobe outcome measures were not stated.

Swartz et $\mathrm{al}^{29}$ treated 11 FTD patients with SSRIs (fluoxetine, $\mathrm{n}=5$; sertraline, $\mathrm{n}=5$; or paroxetine, $\mathrm{n}=1$ ) in an open label study for a minimum of 3 months. The patients met the clinical, neuropsychological, and neuroimaging criteria for FTD that were used to create the Lund-Manchester criteria. There was improvement in disinhibition, depressive symptoms, carbohydrate craving, and compulsions in at least $50 \%$ of subjects who had these problems. The outcome measure was a 7point scale modeled after the CGI change scale. Response to SSRIs was unrelated to baseline MMSE.

Moretti et $\mathrm{al}^{30}$ carried out a randomized, controlled, open label study in 16 patients meeting the fourth edition of the Diagnostic and Statistical Manual of Mental Disorders (DSMIV) ${ }^{31}$ criteria for dementia and Lund-Manchester criteria for FTD. Subjects received paroxetine $(n=8)$ or piracetam $(n=8)$.
Outcome measures were MMSE, Ten Point Clock Test, Proverb Interpretation Tasks, Stroop Test, NPI, Clinical Insight Rating Scale, Cornell Scale for Depression in Dementia, BEHAVE-AD, and the Relative Stress Scale. At 14 months, patients on paroxetine performed significantly better than those on piracetam on the Behavioral Pathology in Alzheimer's Disease Rating Scale (BEHAVE-AD), NPI, Cornell Scale for Depression in Dementia, and Relative Stress Scale; and performance on the NPI and Relative Stress Scale improved in the paroxetine group compared to baseline. There was no improvement in any domain in the piracetam group.

Moretti et $\mathrm{al}^{32}$ studied three patients with FTD who met LundManchester criteria by administering 1-deprenyl, a MAO-B inhibitor, over 3 months. They reported significant improvement on the NPI, as well as improvement on two other measures, i.e., Stroop Test, $(\mathrm{p}=0.0567)$ and Paced Auditory Serial Addition Task $(\mathrm{p}=0.056)$.

Adler et $\mathrm{al}^{33}$ studied the effects of moclobemide, a selective and reversible MAO-A inhibitor, in a 4-week open label trial of six patients with FTD who met the criteria formulated by McKhann et al. ${ }^{3}$ There was improvement in various domains, primarily affect, behaviour, and speech. Specific tests used as outcome measures were not stated.

Ikeda et $\mathrm{al}^{34}$ studied fluvoxamine in an open label 12-week trial of 16 subjects with FTLD diagnosed according to the Neary et al criteria. Eleven had FTD and five had SD. The goal was to determine whether behavioural symptoms, especially stereotyped behaviours, would improve. There was significant improvement on the NPI total score and aberrant motor behavior subscale, and on the Stereotypy Rating Inventory ${ }^{35}$ total score and following subscales: eating and cooking, roaming, speaking, movements, and daily rhythm. There was no significant change in MMSE scores. The response to treatment was not analyzed for FTD and SD separately.

Moretti et $\mathrm{al}^{36}$ carried out a 12 month open label study of rivastigmine in subjects who met Lund-Manchester criteria for FTD and DSM-IV criteria for dementia. Twenty subjects received rivastigmine and 20 received "standard" treatment with antipsychotics, benzodiazepines, and selegiline. Outcome measures included the NPI, Cornell Scale for Depression in Dementia, BEHAVE-AD, Relative Stress Scale, Clinical Insight Rating Scale, MMSE, Ten Point Clock Test, and Proverb Interpretation Tasks. The authors reported significant benefit in the rivastigmine group on the NPI, BEHAVE-AD, Cornell Scale for Depression in Dementia, Relative Stress Scale, and executive function. ${ }^{36}$

Lampl et $\mathrm{al}^{37}$ studied nine subjects with FTD who were treated with donepezil or rivastigmine and who were diagnosed according to the criteria by McKhann et al. Outcome measures included SPECT imaging, MMSE, and clock drawing. The were four males and five females. The four males showed clinically significant improvement that was also demonstrated on SPECT in three cases. Three women showed only very slight improvement initially.

$\mathrm{Chow}^{38}$ described a series of 35 cases with FTLD (FTD, SD, and PA) who were treated with a variety of medications, including SSRIs. Diagnosis was based on the Neary et al criteria. Improvement was defined by a caregiver's report or the clinician's objective observation of improvement. Obsessive- 
compulsive behaviours responded positively in the majority of subjects who were given paroxetine (8/11); however, there was no head-to-head comparison with other SSRIs. Also, SSRIs reduced anxiety but there was no improvement in depressive symptoms.

Moretti et al $^{39}$ reported 17 patients who were treated with olanzapine and who met Lund-Manchester criteria for FTD and DSM-IV criteria for dementia. Patients were followed for 24 months. Outcome measures included the MMSE, Ten Point Clock drawing test, word fluency, Ten Proverb Test, a visuospatial skills test, activities of daily living measures, NPI, Cornell Scale for Depression in Dementia, BEHAVE-AD, Clinical Insight Rating Scale and Relative Stress Scale. Improvement was noted in delusions, rapid behavioral changes such as sudden weeping, NPI, BEHAVE-AD, and caregiver stress. Curtis and $\operatorname{Resch}^{40}$ reported a single case with FTD who was treated with risperidone. Improvement was noted in psychosis and social function. There also seemed to be better motivation and insight. Diagnostic criteria were not stated and there were no formal outcome measures.

Drayton et al. ${ }^{41}$ carried out a retrospective chart review which included eight patients with FTD who were treated with amantadine. Five patients were considered to be responders based on a 7-point Clinical Global Impression Scale. One patient showed an equivocal response. Diagnostic criteria for FTD were not stated.

Mendez et $\mathrm{al}^{42}$ studied eight FTD patients with stereotypical movements who were treated with sertraline for six months. All patients met the Neary et al criteria for FTD. Frontally predominant, anterior temporally predominant, or frontotemporal changes on SPECT or PET were also required for diagnosis of FTD. After treatment with sertraline, there was a significant decline in stereotypical movements on the Abnormal Involuntary Movements Scale.

Chow $^{43}$ treated seven patients meeting the Neary et al criteria for FTD with guanfacine for four months. The study was reported in abstract form. Outcome measures included a continuous performance task, forwards and backwards digit span, Stroop Reading and Interference Tests, Trails A and B, and NPI. There was no statistically significant improvement.

The following are single case reports. Goforth et $\mathrm{al}^{44}$ reported improvement in quantitative electroencephalography in a patient with FTD who was treated with methylphenidate. There was also clinical improvement. Of note is that buproprion was added to augment the effects of methylphenidate. The authors state that the patient's personality reverted to near normal. Diagnosis was based upon criteria formulated by the Lund-Manchester groups and by McKhann et al. Lara et $\mathrm{al}^{45}$ reported improvement in aggression in a patient with FTD who was treated with allopurinol for six weeks. Outcome measures were the Modified Overt Aggression Scale and the Brief Psychiatric Rating Scale. Diagnostic criteria for FTD were not stated. Imamura et $\mathrm{al}^{46}$ reported improvement in recurrent and stuck-in-set types of perseveration after treatment with bromocriptine for 25 days in a patient who met Lund-Manchester criteria for FTD. A battery of 12 tests was used to detect perseveration. Frontal function was also assessed. In addition, the Alzheimer Disease Assessment Scale and digit span were administered.

Thus, several drugs have been tested in FTD with positive results, including trazodone, idazoxan, SSRIs, lithium plus fluoxetine, lithium plus paroxetine, 1-deprenyl, moclobemide, methylphenidate, rivastigmine, donepezil, olanzapine, risperidone, amantadine, allopurinol, and bromocriptine; however, the data are not based on large-scale trials and only six studies were double-blind placebo-controlled trials.

In addition to the above, Richard et al used calcium EDTA, a heavy metal chelator, to treat patients with Pick's disease ${ }^{47-49}$ which is part of the spectrum of what was subsequently termed FTLD. ${ }^{1}$ The rationale was based on the hypothesis that the primary defect in Pick's disease was an excess of zinc. Results included improvement in attention, contact, collaboration, initiative, communication, verbal fluency and comprehension, as well as a reduction in perseveration, echolalia, and verbal stereotypies. There was also improvement in prefrontal signs when present. In addition, the EEG improved in several cases.

Although the general principles applying to studies in Alzheimer's disease are applicable to FTD, there is a major divergence with regard to the ethics of using placebo controls. In Alzheimer's disease, placebo use would deny patients therapies that are now standards of practice. Currently, this concern does not apply to FTD, a condition in which there is no proven therapy.

Another critical issue in clinical trial design is the choice of outcome measures. Tests used in FTD trials include: NPI; FBI; Aphasia Quotient of the Western Aphasia Battery (WAB); Dementia Rating Scale-2; subscales of the WAB and FBI; Cambridge Behavioral Inventory; Tower of London; verbal fluency, rapid visual information processing; paired associates learning; pattern and spatial recognition; digit span; immediate and delayed pattern recognition; spatial span; spatial working memory; visual discrimination learning/attentional set shifting; Cambridge Gamble Task; MMSE; Clinical Global Impressions (CGI); 7-point scale modeled after the CGI change scale; clock drawing; proverb interpretation tasks; Stroop Test; Clinical Insight Rating Scale; Cornell Scale for Depression in Dementia; BEHAVE-AD; Relative Stress Scale; Paced Auditory Serial Addition Task; Stereotypy Rating Inventory; ID/ED attentional set-shifting task; delayed matching to sample; logical memory test; visuospatial skills test; activities of daily living measures; Abnormal Involuntary Movements Scale; Trails A and B; continuous performance task; Modified Overt Aggression Scale; Brief Psychiatric Rating Scale; measures of perseveration; Alzheimer Disease Assessment Scale; quantitative EEG and SPECT imaging. Based on this broad variety of outcome measures, it is evident that there is no strategy or consensus on uniform tasks for use across treatment trials in FTD.

Outcome measures should include measures of cognition that are based on a solid rationale and are well-validated and sensitive to change over relatively short time intervals. In early stages, FTD affects primarily social cognitive function, which may reflect orbitofrontal involvement; however, most standard neuropsychological tests of frontal lobe function are sensitive to dorsolateral frontal function and are relatively insensitive to orbitofrontal function. ${ }^{50,51}$ Therapeutic trials in FTD should include neuropsychological tests of social cognition, which are sensitive to FTD, such as Theory of Mind tasks. ${ }^{51}$ In addition, there should be tests of orbitofrontal function that tap into measures outside the social cognitive realm. An example is 
object alternation, a measure of ability to shift sets and working memory for objects ${ }^{52}$ and which is sensitive to FTD. ${ }^{53}$ Ideally, a single global measure should be developed that taps into a broad spectrum of social cognitive and other orbitofrontal functions. This will minimize the number of primary outcome measures. Outcome measures that tap into a variety of other frontal functions should also be considered as a supplement to a social cognitive/orbitofrontal measure. Candidates include the Executive Interview (EXIT), ${ }^{54}$ Frontal Assessment Battery $(\mathrm{FAB}){ }^{55}$ and Addenbrooke's Cognitive Examination (ACE) ${ }^{56}$ More selective tasks such as Wisconsin Card Sorting Test ${ }^{57}$ and clock drawing ${ }^{58}$ should also be considered.

Outcome measures should also be used to assess the behavioural disturbances commonly seen in FTD, such as apathy and disinhibition. Potential candidates include the NPI, ${ }^{59}$ which has been used in several therapeutic trials, the FBI, ${ }^{60-62}$ and the Frontal Systems Behavior Scale (FrSBe), which was formerly called the Frontal Lobe Personality Scale (FLOPS). ${ }^{63,64}$ Behavioural measures may have better diagnostic utility for FTD as compared to standard cognitive tests. ${ }^{62}$ However, further studies are required to determine whether behavioural measures provide a better strategy for assessing the effects of pharmacological interventions than the use of cognitive measures, including tests of social cognition (e.g., ToM tasks) and cognitive tests of orbitofrontal function (e.g., object alternation task).

Measures such as the Disability Assessment for Dementia ${ }^{65}$ and Clinician's Interview-Based Impression of Change plus Caregiver Input, ${ }^{66}$ as well as measures of caregiver stress, should be standard. The NPI Caregiver Distress Scale $^{67}$ has been developed as an adjunct to the NPI and would be a reasonable choice if the NPI is used. Other possibilities include the Relative Stress Scale.$^{68}$ In addition, measures of quality of life should be considered.

Outcome measures should also be defined for the full range of severity in FTD, although these may differ according to stage of disease. An appropriate measure of overall severity as an inclusion criterion is essential. Whereas the MMSE has become a standard for staging clinical severity in Alzheimer's disease, this test is relatively insensitive to early FTD and thus a more suitable measure is required. Candidates for consideration include the NPI, FBI, and FrSBe. Other options include the Clinical Dementia Rating Scale (CDR). ${ }^{69,70}$

Finally, there is a critical issue relating to differences in diagnostic criteria ${ }^{1,3,25,50}$ and terminology ${ }^{2,26}$ that may hinder comparison across therapeutic trials. There is a need for consensus on diagnostic criteria and terminology among investigators.

Whereas speech-language pathologists commonly attempt to manage language-based symptoms of SD and PA using speech therapy, pharmacological approaches to FTLD have focused on FTD. The general principles outlined for FTD also apply to PA and SD, although specific outcome measures will need to be tailored to the language deficits in these disorders.

In conclusion, there are currently no formal standards for therapeutic trials in FTD. It is recommended that experts in FTD arrive at a consensus to define standards for all clinical trials in FTD. These should include standards for diagnostic criteria, tests of severity, experimental design, and outcome measures.

\section{DeClaration}

During the preparation of this paper, M. Freedman held a research grant from the Canadian Institutes of Health Research and was supported by the Saul A. Silverman Family Foundation, Toronto, Ontario, Canada, as part of a Canada International Scientific Exchange Program project. He has also received funding from Pfizer and Eli Lilly, honoraria for CME from Janssen-Ortho, Lundbeck, Novartis and Pfizer and honoraria for consulting from Janssen, Novartis and Pfizer.

\section{REFERENCES}

1. Neary D, Snowden JS, Gustafson L, Passant U, Stuss D, Black S, et al. Frontotemporal lobar degeneration: a consensus on clinical diagnostic criteria. Neurology. 1998; 51:1546-54.

2. Hodges JR, Miller B. The classification, genetics and neuropathology of frontotemporal dementia. Introduction to the special topic papers: Part I. Neurocase. 2001; 7:31-5.

3. McKhann GM, Albert MS, Grossman M, Miller B, Dickson D, Trojanowski JQ. Clinical and pathological diagnosis of frontotemporal dementia: report of the work group on frontotemporal dementia and Pick's disease. Arch Neurol. 2001; 58:1803-9.

4. Ratnavalli E, Brayne C, Dawson K, Hodges JR. The prevalence of frontotemporal dementia. Neurology. 2002; 58:1615-21.

5 . Ikeda M, Ishikawa T, Tanabe H. Epidemiology of frontotemporal lobar degeneration. Dement Geriatr Cogn Disord. 2004; 17: 265-8.

6. Gustafson L, Brun A. Frontal lobe degeneration of non-Alzheimer type and its relation to other frontotemporal dementias and Alzheimer's disease. In: Kertesz A, Munoz DG, editors. Pick's disease and Pick complex. Toronto: Wiley-Liss; 1998. p. 33-46.

7. Rosso SM, Donker Kaat L, Baks T, Joosee M, de Koning I, Pijnenburg Y, et al. Frontotemporal dementia in the Netherlands: patient characteristics and prevalence estimates from a population-based study. Brain. 2003; 126: 2016-22.

8. Imamura T, Hirono N, Hashimoto M, Shimomura T, Tanimukai S, Kazui H, et al. Clinical diagnosis of dementia with Lewy bodies in a Japanese dementia registry. Dement Geriatr Cogn Disord. 1999; 10:210-6.

9. Knopman DS, Mastri AR, Frey WH, Sung JH 2nd, Rustan T. Dementia lacking distinctive histological features: a common non-Alzheimer degenerative dementia. Neurology. 1990; 40:2516.

10. Barker WW, Luis CA, Kashuba A, Luis M, Harwood DG, Loewenstein D, et al. Relative frequencies of Alzheimer disease, Lewy body, vascular and frontotemporal dementia, and hippocampal sclerosis in the State of Florida Brain Bank. Alzheimer Dis Assoc Disord. 2002; 16:203-12.

11. Giannakopoulos P, Hof PR, Bouras C. Dementia lacking distinctive histopathology: clinicopathological evaluation of 32 cases. Acta Neuropathol (Berl). 1995; 89:346-55.

12. Brun A. Frontal lobe degeneration of non-Alzheimer type. I. Neuropathology. Arch Gerontol Geriatr. 1987; 6:193-208.

13 . Sparks D L, Markesbery W R. Altered serotonergic and cholinergic synaptic markers in Pick's disease. Arch Neurol. 1991; 48:796-9.

14 . Sjögren M, Minthon L, Passant U, Blennow K, Wallin A. Decreased monoamine metabolites in frontotemporal dementia and Alzheimer's disease. Neurobiol Aging. 1998; 19:379-84.

15 . Proctor AW, Qurne M, Francis PT. Neurochemical features of frontotemporal dementia. Dement Geriatr Cogn Disord. 1999; 10:80-4.

16. Perry RJ, Miller BL. Behavior and treatment in frontotemporal dementia. Neurology. 2001; 56:S46-51.

17 . Pasquier F, Fukui T, Sarazin M, Pijnenburg Y, Diehl J, Grundman $\mathrm{M}$, et al. Laboratory investigations and treatment in frontotemporal dementia. Ann Neurol. 2003; 54:S32-5. 
18. Sahakian BJ, Coull JJ, Hodges JR. Selective enhancement of executive function by idazoxan in a patient with dementia of the frontal lobe type. J Neurol Neurosurg Psychiatry. 1994; 57: $120-1$.

19. Coull JT, Sahakian BJ, Hodges JR. The alpha(2) antagonist idazoxan remediates certain attentional and executive dysfunction in patients with dementia of frontal type. Psychopharmacology (Berl). 1996; 123:239-49.

20 . Lebert F, Stekke W, Hasenbroekx C, Pasquier F. Frontotemporal dementia: a randomized, controlled trial with Trazodone. Dement Geriatr Cogn Disord. 2004; 17:355-9.

21. Deakin JB, Rahman S, Nestor PJ, Hodges JR, Sahakian BJ. Paroxetine does not improve symptoms and impairs cognition in frontotemporal dementia: a double-blind randomized controlled trial. Psychopharmacology (Berl). 2004; 172:400-8.

22. Kertesz A, Blair M, Davidson W, Light M, Morlog D, Brashear R. A pilot study of the safety and efficacy of galantamine for Pick complex/frontotemporal dementia (FTD). Ann Neurol. 2005; 58:S47.

23. Rahman S, Robbins TW, Hodges JR, Mehta MA, Nestor PJ, Clark L, et al. Methylphenidate ('Ritalin') can ameliorate abnormal risktaking behavior in the frontal variant of frontotemporal dementia. Neuropsycho pharmacology. 2006; 31:651-8.

24 . Gregory CA, Hodges JR. Dementia of frontal type and the focal lobar atrophies. Int Rev Psychiatry. 1993; 5:397-406.

25 . The Lund and Manchester Groups. Clinical and neuropathological criteria for frontotemporal dementia. J Neurol Neurosurg Psychiatry. 1994; 57:416-8.

26 . Kertesz A. Pick's disease and Pick complex: introductory nosology. In: Kertesz A, Munoz DG, editors. Pick's disease and Pick complex. Toronto: Wiley-Liss; 1998. p. 1-11.

27. Lebert F, Pasquier F. Trazodone in the treatment of behavior in frontotemporal dementia. Hum Psychopharmacol Clin Exp. $1999 ; 14: 279-81$

28. Anderson IM, Scott K, Harborne G. Serotonin and depression in frontal lobe dementia. Am J Psychiatry. 1995; 152:645.

29. Swartz JR, Miller BL, Lesser IM, Darby AL. Frontotemporal dementia: treatment response to serotonin selective reuptake inhibitors [erratum appears in J Clin Psychiatry 1997 Jun;58(6):275]. J Clin Psychiatry. 1997; 58:212-6.

30 . Moretti R, Torre P, Antonello RM, Cazzato G, Bava A. Frontotemporal dementia: paroxetine as a possible treatment of behavior symptoms. A randomized, controlled, open 14-month study. Eur Neurol. 2003; 49:13-9.

31. American Psychiatric Association. DSM-IV: Diagnostic and statistical manual of mental disorders. 4th ed. Washington, D.C.: American Psychiatric Association, 1994.

32 . Moretti R, Torre P, Antonello RM, Cazzato G, Bava A. Effects of selegiline on fronto-temporal dementia: a neuropsychological evaluation. Int J Geriatr Psychiatry. 2002; 17:391-2.

33. Adler G, Teufel M, Drach LM. Pharmacological treatment of frontotemporal dementia: treatment response to the MAO-A inhibitor moclobemide. Int J Geriatr Psychiatry. 2003; 18:653-5.

34 . Ikeda M, Shigenobu K, Fukuhara R, Hokoishi K, Maki N, Nebu A, et al. Efficacy of fluvoxamine as a treatment for behavioral symptoms in frontotemporal lobar degeneration patients. Dement Geriatr Cogn Disord. 2004; 17:117-21.

35 . Shigenobu K, Ikeda M, Fukuhara R, Maki N, Hokoishi K, Nebu A, et al. The stereotypy rating inventory for frontotemporal lobar degeneration. Psychiatry Res. 2002; 110:175-87.

36. Moretti R, Torre P, Antonello RM, Cattaruzza T, Cazzato G, Bava A. Rivastigmine in frontotemporal dementia: an open-label study. Drugs Aging. 2004; 21:931-7.

37 . Lampl Y, Sadeh M, Lorberboym M. Efficacy of acetylcholinesterase inhibitors in frontotemporal dementia. Ann Pharmacother. 2004; 38:1967-8.

38. Chow TW, Mendez MF. Goals in symptomatic pharmacologic management of frontotemporal lobar degeneration. Am J Alzheimers Dis Other Demen. 2002; 17:267-72.

39 . Moretti R, Torre P, Antonello RM, Cazzato G, Griggio S, Bava A. Olanzapine as a treatment of neuropsychiatric disorders of Alzheimer's disease and other dementias: a 24-month follow-up of 68 patients. Am J Alzheimers Dis Other Demen. 2003; 18: 205-14.
40. Curtis RC, Resch DS. Case of Pick's central lobar atrophy with apparent stabilization of cognitive decline after treatment with risperidone. J Clin Psychopharmacol. 2000; 20:384-5.

41 . Drayton SJ, Davies K, Steinberg M, Leroi I, Rosenblatt A, Lyketsos CG. Amantadine for executive dysfunction syndrome in patients with dementia. Psychosomatics. 2004; 45:205-9.

42 . Mendez MF, Shapira JS, Miller BL. Stereotypical movements and frontotemporal dementia. Mov Disord. 2005; 20:742-5.

43 . Chow TW. Open label trial of guanfacine for symptomatic treatment of frontotemporal dementia. J Neuropsychiatry Clin Neurosci. 2002; 14:110

44 . Goforth HW, Konopka L, Primeau M, Ruth A, O’Donnell K, Patel $\mathrm{R}$, et al. Quantitative electroencephalography in frontotemporal dementia with methylphenidate response: a case study. Clin EEG Neurosci. 2004; 35:108-11.

45. Lara DR, Cruz MR, Xavier F, Souza DO, Moriguchi EH. Allopurinol for the treatment of aggressive behaviour in patients with dementia. Int Clin Psychopharmacol. 2003; 18:53-5.

46. Imamura T, Takanashi M, Hattori N, Fujimori M, Yamashita H, Ishii $\mathrm{K}$, et al. Bromocriptine treatment for perseveration in demented patients. Alzheimer Dis Assoc Disord. 1998; 12:109-13.

47 . Richard J, Constantinidis J, Tissot R. Calcium EDTA treatment of Pick's disease. Nouv Presse Med. 1978; 7:1304.

48. Constantinidis J, Tissot R. Role of glutamate and zinc in the hippocampal lesions of Pick's disease. Adv Biochem Psychopharmacol. 1981; 27:413-22.

49. Richard J, Constantinidis J, Tissot R. Maladie de PICK et metabolisme du zinc. Arguments pour une nouvelle hypothese pathogenique et premiers resultats d'un traitement prolonge par l'EDTA calcique. In: Muller C, Wertheimer J, editors. Gerontopsychiatrie 7. Janssen Pharmaceutica; 1979. p. 83-8.

50 . Gregory CA, Serra-Mestres J, Hodges JR. Early diagnosis of the frontal variant of frontotemporal dementia: how sensitive are standard neuroimaging and neuropsychologic tests? Neuropsychiatry Neuropsychol Behav Neurol. 1999; 12:128-35.

51. Gregory C, Lough S, Stone V, Erzinclioglu S, Martin L, BaronCohen S, et al. Theory of mind in patients with frontal variant frontotemporal dementia and Alzheimer's disease: theoretical and practical implications. Brain. 2002; 125:752-64.

52. Freedman M, Black S, Ebert P, Binns M. Orbitofrontal function, object alternation and perseveration. Cereb Cortex. 1998; 8: 18-27.

53. Freedman M, Binns MA, Black SE, Levine B, Miller B, Stuss DT. Object Alternation: A cognitive and diagnostic measure of orbitofrontal function in frontotemporal dementia. Neurology. 2003; Suppl 1:A264.

54 . Royall DR, Mahurin RK, Gray KF. Bedside assessement of executive cognitive impairment: The executive interview. J Am Geriatr Soc. 1992; 40:1221-6.

55. Dubois B, Slachevsky A, Litvan I, Pillon B. The FAB: A frontal assessment battery at bedside. Neurology. 2000; 55:1621-6.

56 . Mathuranath PS, Nestor PJ, Berrios GE, Rakowicz W, Hodges JR. A brief cognitive test battery to differentiate Alzheimer's disease and frontotemporal dementia. Neurology. 2000; 55:1613-20.

57. Heaton RK. Wisconsin Card Sorting Test Manual. Florida: Psychological Assessment Resources Inc., 1981.

58 . Freedman M, Leach L, Kaplan E, Winocur G, Shulman KI, Delis D. Clock drawing: a neuropsychological analysis. New York: Oxford University Press 1994.

59. Cummings JL, Mega M, Gray K, Rosenberg-Thompson S, Carusi DA, Gornbein J. The neuropsychiatric inventory: Comprehensive assessment of psychopathology in dementia. Neurology. 1994; 44:2308-14.

60. Kertesz A, Davidson W, Fox H. Frontal behavioral inventory: Diagnostic criteria for frontal lobe dementia. Can J Neurol Sci. 1997; 24:29-36

61. Kertesz A, Nadkarni N, Davidson W, Thomas AW. The frontal behavioral inventory in the differential diagnosis of frontotemporal dementia. J Int Neuropsychol Soc. 2000; 6:460-8.

62. Kertesz A, Davidson W, McCabe P, Munoz D. Behavioral quantitation is more sensitive than cognitive testing in frontotemporal dementia. Alzheimer Dis Assoc Disord. 2003; 17:223-9. 
63. Grace J, Stout JC, Malloy PF. Assessing frontal lobe behavioral syndromes with The Frontal Lobe Personality Scale. Assessment. 1999; 6:269-84.

64 . Stout JC, Ready RE, Grace J, Malloy PF, Paulsen JS. Factor analysis of the frontal systems behavior scale (FrSBe). Assessment. 2003; 10:79-85.

65. Gelinas I, Gauthier L, McIntyre M, Gauthier S. Development of a functional measure for persons with Alzheimer's disease: the disability assessment for dementia. Am J Occup Ther. 1999; 53:471-81.

66 . Schneider LS, Olin JT, Doody RS, Clark CM, Morris JC, Reisberg $\mathrm{B}$, et al. Validity and reliability of the Alzheimer's disease cooperative study-clinical global impression of change. Alzheimer Dis Assoc Disord. 1997; 11:S22-32.

67. Kaufer DI, Cummings JL, Christine D, Bray T, Castellon S, Masterman D, et al. Assessing the impact of neuropsychiatric symptoms in Alzheimer's disease: the neuropsychiatric inventory caregiver distress scale. J Am Geriatr Soc. 1998; 46:210-5.
68. Greene JG, Smith R, Gardiner M, Timbury GC. Measuring behavioral disturbance of elderly demented patients in the community and its effects on relatives: a factor analytic study. Age Ageing. 1982; 11:121-6.

69 . Hughes CP, Berg L, Danziger WL, Coben LA, Martin RL. A new clinical scale for the staging of dementia. Br J Psychiatry. 1982; 140:566-72.

70 . Morris JC. The clinical dementia rating (CDR): current version and scoring rules. Neurology. 1993; 43:2412-4. 